\title{
Review of Failure Probability Calculations for HFIR Primary Coolant System Piping
}

F. A. Simonen

October 2001

Prepared for the U.S. Department of Energy under Contract DE-AC06-76RL01830 


\title{
DISCLAIMER
}

This report was prepared as an account of work sponsored by an agency of the United States Government. Neither the United States Government nor any agency thereof, nor Battelle Memorial Institute, nor any of their employees, makes any warranty, express or implied, or assumes any legal liability or responsibility for the accuracy, completeness, or usefulness of any information, apparatus, product, or process disclosed, or represents that its use would not infringe privately owned rights. Reference herein to any specific commercial product, process, or service by trade name, trademark, manufacturer, or otherwise does not necessarily constitute or imply its endorsement, recommendation, or favoring by the United States Government or any agency thereof, or Battelle Memorial Institute. The views and opinions of authors expressed herein do not necessarily state or reflect those of the United States Government or any agency thereof.

\author{
PACIFIC NORTHWEST NATIONAL LABORATORY \\ operated by \\ BATTELLE \\ for the \\ UNITED STATES DEPARTMENT OF ENERGY \\ under Contract DE-ACO6-76RLO183O
}

Printed in the United States of America

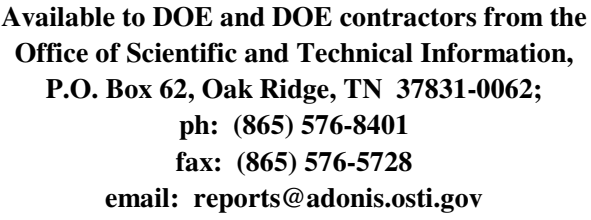
Available to the public from the National Technical Information Service, U.S. Department of Commerce, 5285 Port Royal Rd., Springfield, VA 22161 ph: (800) 553-6847 fax: $(703) 605-6900$ email: orders@ntis.fedworld.gov online ordering: http://www.ntis.gov/ordering.htm


PNNL-13718

\section{Review of Failure Probability Calculations for HFIR Primary Coolant System Piping}

F. A. Simonen

October 2001

Prepared for

the U.S. Department of Energy

under Contract DE-AC06-76RL01830

Pacific Northwest National Laboratory

Richland, Washington 99352 


\section{Summary}

During July 2001, Pacific Northwest National Laboratory was requested by the U.S. Department of Energy, Office of Nuclear Facilities Management, Office of Nuclear Energy, Science and Technology, Germantown, Maryland, to review calculations of piping failure probabilities for the High Flux Test Reactor (HFIR) located at and operated by the Oak Ridge National Laboratory (ORNL). The objective of the failure probability calculations was to estimate the probabilities of large leaks (>1500 gpm) that are of sufficient size to disable the primary coolant system of HFIR to the extent that there is a potential for core damage. PNNL reviewed the computational methods and the inputs to the calculations along with an evaluation of potential failure mechanisms not explicitly addressed by the ORNL calculations. The review concluded that the calculated failure probabilities even with consideration of uncertainties in the calculations and of other potential failure mechanisms provide a high level of confidence that failure frequencies are less than the stated goal of $10^{-6}$ piping failures per year. 


\section{Contents}

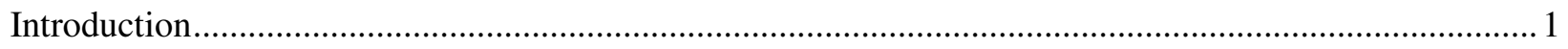

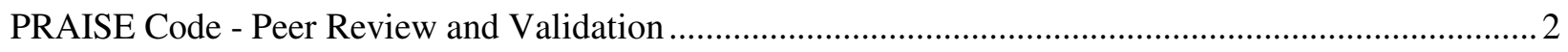

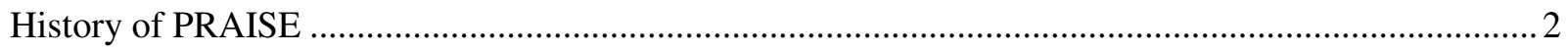

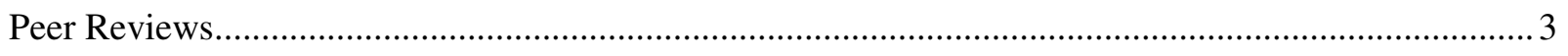

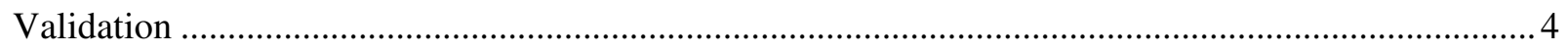

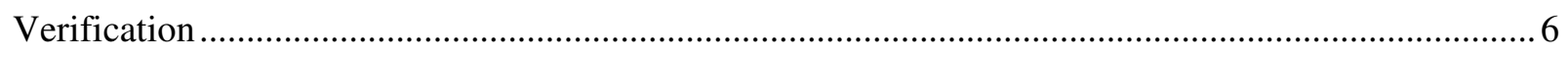

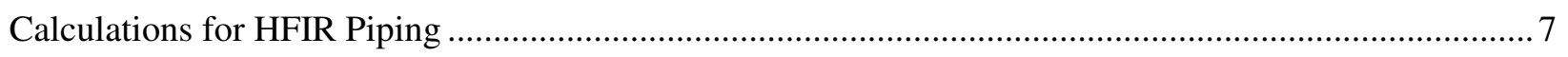

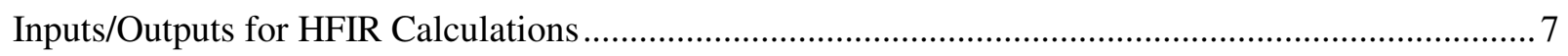

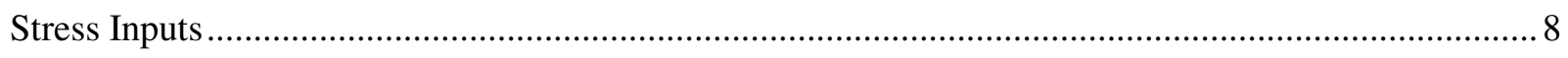

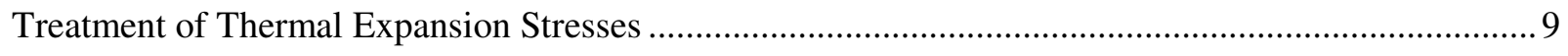

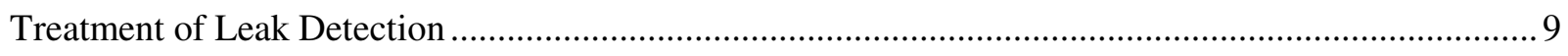

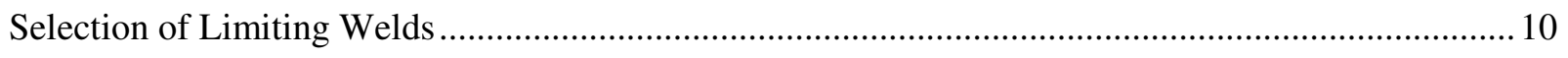

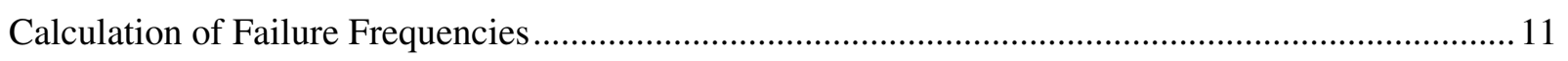

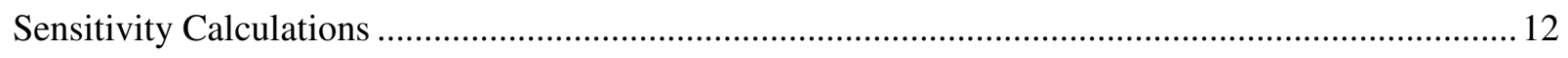

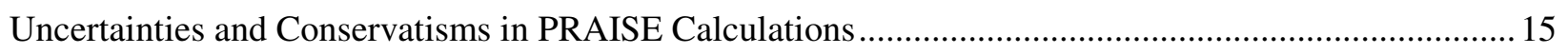

Evaluation of Uncertainties in Probabilistic Calculations ............................................................ 15

Conservatisms in PRAISE Fracture Mechanics Model ................................................................. 17

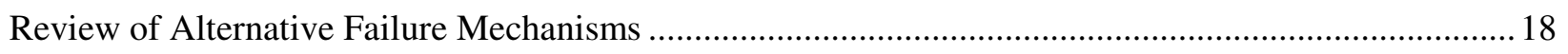

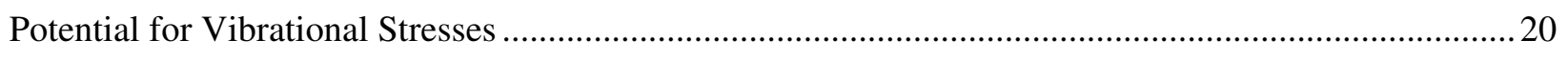

Data on Vibrational Fatigue Failures at Commercial Nuclear Power Plants .....................................20

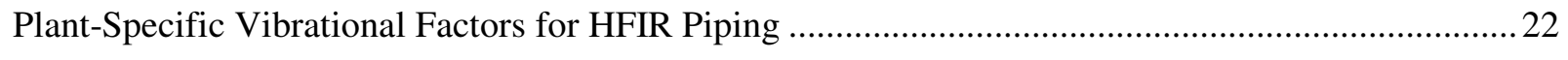

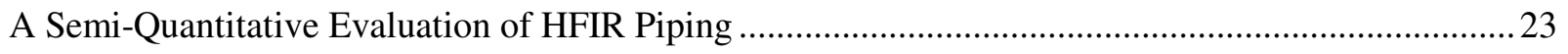


Exploratory Calculations with PRAISE ....

Conclusions on Potential for Vibrational Fatigue

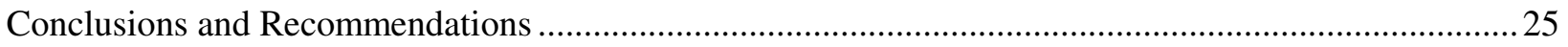

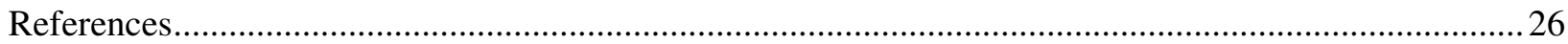




\section{Figures}

1 Estimates of Small Leak Probabilities Based on Guidance of NUREG-1661 ............................... 14

2 Histogram for Probability of Failure Calculated by PRAISE ................................................... 16

3 Upper and Lower Bounds of Leak and Break Probabilities from Uncertainty Analyses ................ 16

4 Probabilities from Uncertainty Analyses Compared to Best Estimate Calculations ....................... 17

5 Service Failures in Small Bore Piping $(<2$ inch NPS) ....................................................... 21

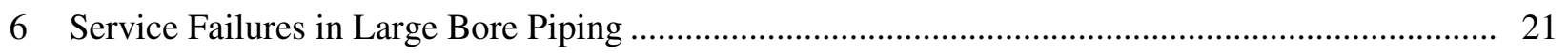

7 Vibrational Fatigue Failures Showing Decrease In Failure Rate as Plants Become Older .............. 24 


\section{Introduction}

Pacific Northwest National Laboratory (PNNL) during July 2001 was requested by the U.S. Department of Energy, Office of Nuclear Facilities Management, Office of Nuclear Energy, Science and Technology, Germantown, Maryland, to review calculations of piping failure probabilities for the High Flux Test Reactor (HFIR) located at and operated by the Oak Ridge National Laboratory (ORNL). The present report reviews calculations for HFIR piping that was performed by ORNL with the assistance of Dr. David Harris of Engineering Mechanics Technology, Inc. (EMT). PNNL's review was based on information presented in an ORNL report titled Probability of Failure of the HFIR Primary Piping (Cherverton 2001) and Safety Analysis to Resolve the USQ Regarding Discovery of a Cracked Pipe in HFIR PWD Drain Line (Ramsey et al. 2001), a background briefing at a meeting (held at ORNL on August 2, 2001), a set of computer outputs received on August $13^{\text {th }}$ from Dr. Harris, and several teleconferences with ORNL and EMT staff.

The objective of the failure probability calculations was to estimate the frequencies of larger leaks that are sufficient size to disable the primary coolant system of HFIR to the extent that core damage can result. The ORNL approach was to first calculate failure probabilities for individual girth welds of concern and then to calculate an overall probability of failure for the piping of the primary coolant system. A "best estimate" system level probability of a large system disabling leak of $10^{-6}$ per year was stated as being sufficiently small to classify the failure event as a "beyond design basis event." Accordingly, PNNL has reviewed the calculated failure probabilities to determine if the probabilities as calculated along with consideration of the uncertainties in the calculations provide a high level of confidence that the frequencies are less than the goal of $10^{-6}$ piping failures per year.

The review consisted of the following:

(1) The main objective of PNNL's review was to examine the inputs and outputs of the probabilistic fracture mechanics calculations in sufficient detail to determine if the calculations adequately support the conclusion that failure frequencies for large disabling leaks in the HFIR piping system are very small and consistent with an annual failure frequency of less than $10^{-6}$.

(2) Because the PRAISE computer code was applied to calculate failure probabilities, PNNL's review addressed the extent to which this code has been subject to technical peer review and verification/validation efforts.

(3) Uncertainties and conservatisms in both the inputs to PRAISE and in the fracture mechanics models themselves were reviewed and were quantified to the extent possible.

(4) Because the calculations with the PRAISE code addressed only piping failures due to low cycle fatigue associated with fabrication flaws in welds, PNNL considered the potential for alternative failure mechanisms such as stress corrosion cracking and high cycle fatigue from vibrational stresses. 
(5) Because vibrational fatigue was identified as the alternative failure mechanism of potential concern to HFIR piping, this mechanism was evaluated for the design and operating conditions that apply to HFIR piping in sufficient detail to conclude that vibrational fatigue does not need to be considered.

(6) Data bases on piping failures reported from operating nuclear power plants were examined for failure mechanisms and observed failure frequencies that could be applicable to HFIR piping, with special attention to vibrational fatigue failures.

\section{PRAISE Code - Peer Review and Validation}

PNNL performed a review of the PRAISE code during 1999 on behalf of the Nuclear Regulatory Commission (NRC). The discussion below was based on this prior review. In addition, it should also be noted that PNNL staff have performed extensive calculations for NRC with the PRAISE code including studies to benchmark outputs of the code against hand calculations and with results of other probabilistic fracture mechanics code.

The PRAISE code was developed during the early 1980s and has been applied over the years as a research tool. As such, it has not been subjected to formal and documented V\&V processes. However, the discussion below shows that elements of a rigorous $\mathrm{V} \& \mathrm{~V}$ process have been performed over the time frame that the code has been in use by NRC and the nuclear power industry. In these applications PRAISE calculations have supported regulatory decisions and NRC has accepted its use by industry applicants in requesting NRC approval for actions such as implementation of risk informed inspection programs for piping systems.

\section{History of PRAISE}

The development and maintenance of the PRAISE code has been through a series of short-term efforts, each driven by a need to address specific safety issues. As such, there has been no continuity of funding to maintain the code and its documentation or to develop code enhancements on a regular basis. Nevertheless, the PRAISE code has been viewed as a standard for probabilistic fracture mechanics codes, in part because of a lack of competing codes with comparable capabilities. The PRAISE code as it exists today is the result of the following incremental efforts performed over some 20 years:

(1) The initial development was funded by NRC through the Lawrence Livermore National Laboratory (LLNL). This effort during the early 1980s (Harris, Lim, and Dedhia 1981) provided a probabilistic fracture mechanics code to address issues on the Seismic Safety Margins Program. At that time, the capabilities of the Monte Carlo simulation code were limited to piping failures associated with the growth of fabrication flaws in piping welds by the mechanisms of fatigue crack growth and ductile tearing. 
(2) During the mid-to-late 1980s there was a revival of interest in PRAISE as a fracture mechanics code to address failures of stainless steel piping by the mechanism of intergranular stress corrosion cracking. An enhanced version of PRAISE was developed (Harris et al. 1986) to simulate the initiation and growth of stress corrosion cracks.

(3) PRAISE was originally written to run large mainframe computers, such as the Control Data and CRAY machines at LLNL. By the early 1990s, the capabilities of personal computers had increased sufficiently to warrant the conversion of PRAISE to pc-PRAISE (Harris and Dedhia 1991) in order to perform calculations on DOS-based machines.

(4) Starting in the early 1990s, PNNL began research for NRC to develop methodologies for riskinformed inservice inspection. The pc-PRAISE code was applied extensively by PNNL to calculate piping failure probabilities and to evaluate the potential of inservice inspection programs to reduce these failure probabilities (Khaleel and Simonen 1994a, 1994b, 1995, 1997). The original developer of the code (Dr. David Harris now with Engineering Mechanics Technology, Inc.) was engaged as a subcontractor to PNNL to implement enhancements to the code to better simulate the effects of inservice inspections.

(5) During 1997-98, Dr. Harris responded to a need within the nuclear power industry for a probabilistic fracture mechanics code that could support the development of risk-informed inservice inspections on a plant-specific basis. The result was the WinPRAISE code (Harris and Dedhia 1991) that is a proprietary version of pc-PRAISE that features a user-friendly interactive front-end and some other features of particular use to the inspection application. Dr. Harris has marketed this version of the code, but has provided copies to NRC staff and PNNL on a complimentary basis for use on NRC studies.

(6) During 1999, the DOS version of pc-PRAISE was significantly enhanced by the addition of a model for simulating the initiation of fatigue cracks. This model was made possible by the extensive research by Argonne National Laboratory (ANL) on environmentally assisted fatigue (Keisler, Chopra, and Shack 1994, 1995). Funding for the collaborative effort between PNNL and Dr. Harris was part of the resolution of GSI 190. A report (NUREG/CR-6674) was issued during the first quarter of CY2000 to document the enhanced version of pc-PRAISE.

\section{Peer Reviews}

Peer reviews have included formal reviews of the PRAISE code on behalf of NRC by panels of experts as well as publication in peer-reviewed journals and conference proceedings. Peer reviews have included efforts directed to critical elements of the fracture mechanics models, such as equations based on experimental data used to predict the initiation and growth of fatigue and stress corrosion cracks.

The original version PRAISE code was developed as part the Seismic Safety Margins Project at LLNL. As part of this project PRAISE was extensively reviewed by a panel of outside experts. While formal documentation of the reviews may still exist in project files, the present discussion is limited to 
recollections by Dr. Harris and Dr. S. H. Bush. There were several meetings during the early 1980s at LLNL. Panel members included G. E. Apostolakis, S. H. Bush, G. Irwin, and E. Rodabaugh, all nationally recognized experts in fracture mechanics, structural reliability, and risk assessment.

Another peer review panel was organized during the mid 1980s to address the enhancements of PRAISE to address stress corrosion cracking. As a result of these reviews, the initial implementation of the IGSCC model was forced to go through revisions before the final version of the code was released.

PNNL presented results of pc-PRAISE calculations during the early 1990s to the ASME Research Task Force on Risk-Based Inservice Inspection. This group included a number of practitioners of probabilistic fracture mechanics, such as Westinghouse Electric (Bruce Bishop), Pacific Northwest National Laboratory (Fred Simonen), independent consultants (David Harris), and overseas organizations (O.J.V. Chapman from Rolls Royce Marine Power). Inputs from Mr. Chapman were particularly significant in that his work in the area of probabilistic fracture mechanics was performed independently from U.S. efforts.

Probabilistic fracture mechanics codes saw intensive applications during the mid-to-late 1990s on pilot applications of risk-informed inservice inspection. Noteworthy was the use of the SRRA code by Westinghouse Electric on Surry 1 evaluations. The ASME Research Task Force on Risk-Based Inservice Inspection provided a forum for reviewing the methodologies of the SRRA and PRAISE code on a comparative basis (Bishop 1997). The main conclusion of this work was a need to better define critical input parameters to the calculations, with particular concerns with inputs for the number and sizes of fabrication flaws in welds. Both codes greatly benefited from a technology transfer from work performed in the United Kingdom by Rolls Royce.

PNNL published several papers based on the PRAISE code during the 1990s at ASME conferences, in the ASME Journal of Pressure Vessel Technology, and at international conferences on structural reliability and risk (Simonen and Woo 1984; Khaleel and Simonen 1994a, 1994b, 1995, 1997). These publications were subject to the usual peer review process.

The most recent enhancements to pc-PRAISE incorporated the ANL model for predicting probabilities of initiating fatigue cracks. The development of the ANL model was subject to extensive peer review from the international community performing research in the area of environmentally enhanced fatigue. Other reviews of ANL work came from interactions with structural integrity specialists from the nuclear power industry, often through ASME conferences and consensus code bodies.

\section{Validation}

Failure probability predictions of the PRAISE code have been validated with trends from plant operation experience. In contrast, the term validation applies to comparisons of calculated failure probabilities from PRAISE with failure frequencies from plant operating experience. 
Validations have been accomplished more readily for stress corrosion cracking than for fatigue, because there are more data for service-related failures for IGSCC than for mechanical and thermal fatigue. The documentation for the PRAISE code (Harris et al. 1986) and recent papers describing PNNL calculations (Khaleel and Simonen 1995, 1997, Khaleel et al. 1995) have compared calculated failure probabilities as a function of time with failures that have occurred at BWR plants expressed as a function of time since the start of plant operation. Most IGSCC data come from cracking detected before 1990, which corresponds to the time period before plants implemented the mitigating actions that have since significantly reduced the number of IGSCC failures. The validation efforts showed good agreement between calculations and operating experience, and also resulted in modifications (reductions in residual stress levels and reduced damage from load/unload cycles) of the fracture mechanics model to achieve even better agreement with field data.

The number of fatigue failures is insufficient to make many comparisons of predicted versus observed probabilities. Fatigue failures have been associated with mechanical vibration and thermal fatigue. For these failures it is difficult to establish the actual stress levels and number cycles. The most notable attempt to compare PRAISE predictions with service experience was by LLNL (Woo and Chu 1982a, 1982b) in terms of feedwater nozzle cracking that was found at a number of pressurized water reactor (PWR) plants during the 1980s. Calculations with PRAISE were performed for the estimated stress conditions at several plants. The calculations were successful in predicting failure probabilities approaching 1.0 for operating periods similar to those at which the cracking was found to occur in the field.

In another validation for fatigue, the predicted cycles to crack initiation as predicted by the ANL equations were compared to results of fatigue tests performed by Southwest Research Institute of prototypical vessels. Other data from large scale specimens and specimens with realistic surface roughness (rather than the polished surfaces of laboratory test specimens) were compared with predictions based on the ANL equations. This has resulted in ANL recommending reduction in cycles to failure by a factor of 4.0 to enable more realistic predictions for piping components.

As part of the calculations for fatigue crack initiation (GSI-190 resolution) PNNL also reviewed data on service experience on piping fatigue failures. This recent review focused on the relative numbers of reported large leaks (or ruptures) versus the much larger number of small leaks. These trends were used to evaluate predictions from pc-PRAISE and to fine-tune inputs to the failure probability calculations. This effort is summarized in NUREG/CR-6674.

It is useful to cite the comparisons of service experience with predictions from the recent PNNL fatigue calculations. These PRAISE calculations identified a number of components with predicted probabilities of through-wall cracks that would be essentially 100 percent after the 40 -year operating period. This prediction would incorrectly imply that some operating plants have already experienced a relatively large number of leaks. In reality, the high fatigue damage locations do not experience the number or severity of cyclic stresses that were postulated in the design stress reports. Research by EPRI/DOE (Deardorf and Smith 1994) has demonstrated with instrumentation and refined fatigue evaluations that components can experience fatigue usage factors as small as $10 \%$ of the predicted levels. 
Such reductions in fatigue cycling can greatly reduce the predicted probability of through-wall cracks (e.g., from 80 percent to less than 5 percent).

\section{Verification}

The term verification applies to efforts to show that the PRAISE code performs the calculations correctly in the manner that it is said to perform. Such efforts have focused on the running of benchmark problems on codes similar to PRAISE to establish that both codes calculate the same or similar failure probabilities, given that both codes are provided with the same input parameters.

Failure probabilities calculated by PRAISE have been compared on several occasions with failure probabilities calculated by other probabilistic fracture mechanics codes. The following describes a number of these verification (or benchmarking) calculations.

A probabilistic fracture mechanics code (PARIS) was developed in Germany (Bruckner-Foit et al. 1989) with essentially the same methodology as the PRAISE code. These calculations considered only failures caused by fatigue crack growth from preexisting fabrication flaws. The German organization obtained a copy of PRAISE and evaluated the same piping components with the same input parameters using both PARIS and PRAISE. Tables in the 1989 paper show calculated failure probabilities that are very nearly equal. These benchmarking calculations provide assurance that the PRAISE code has correctly implemented the fracture mechanics models and Monte Carlo simulations in the manner stated in the code documentation.

Other fatigue calculations have been performed by Dr. Harris as part of the code development and verification. These calculations were largely performed by exercising the PRAISE code in a deterministic manner and comparing solutions with results from deterministic fracture mechanics codes such as the NASCRAC code developed for aerospace applications (NASCRAC 1990; Harris et al. 1987). These calculations verify fracture mechanics models used in PRAISE.

Some ten years ago there was a benchmarking effort performed by Westinghouse Electric that compared failure probabilities calculated by PRAISE and the Westinghouse developed SRRA code. These calculations were again limited to failures due to preexisting fabrication by the mechanism of fatigue crack growth. The results of the calculations showed the PRAISE and SRRA calculate similar failure probabilities if common input parameters are used for both calculations.

A more recent benchmarking effort was part of the Westinghouse Owners Group pilot application of risk-informed inspection to the Surry-1 plant. Results of this work were reported by Bishop (1997) and Simonen and Harris (1998). Much of this effort was concerned with the selection of appropriate inputs to describe plant-specific piping welds with particular concern with flaw densities and size distributions. Again the benchmarking was limited to piping failures due to fatigue crack growth of preexisting fabrication flaws. The range of parameters (pipe size, levels of cyclic stresses, etc.) was much greater than addressed by the prior benchmarking of PRAISE and SRRA. As in the earlier work the two codes were found to give essentially the same failure probabilities if same values of input parameters are used 
by the two codes. There were, however, a few cases from the large matrix of calculations where the SRRA code gave different probabilities than PRAISE. A few SRRA probabilities were much larger than even bounding values of probabilities based on closed form calculations. The differences were limited to examples that had very low probabilities and then only when the calculations included the effects of leak detection on failure rates. The benchmarking effort ended before the reason for the anomalous results from the SRRA code could be established.

There have been not yet been any benchmarking calculations to verify the stress corrosion cracking model of the PRAISE code, because there are no other comparable fracture mechanics codes that addresses stress corrosion cracking. The focus for stress corrosion cracking has therefore been in comparing results of calculations with trends from plant operation experience.

The most recent version of the PRAISE code simulates piping failures caused by the initiation and growth of fatigue cracks. Benchmarking of PRAISE has been performed by comparing calculated failure probabilities with results of an independently develop PNNL code (Khaleel and Simonen 1998) based on a Latin hypercube methodology rather than a Monte Carlo simulation. The two codes give identical probabilities of fatigue crack initiation and similar probabilities of through-wall cracks. The PNNL code uses a simplified fracture mechanics model that gives somewhat higher crack growth rates. As a result the probabilities of through-wall crack are somewhat greater. The differences were greatest for thin-wall pipes and for cases that had relatively low crack initiation probabilities.

\section{Calculations for HFIR Piping}

Part of PNNL's review addressed details of the PRAISE calculations for the HFIR piping and focused on inputs to the probabilistic fracture mechanics calculations rather than the technical basis of the code.

\section{Inputs/Outputs for HFIR Calculations}

PNNL reviewed inputs and outputs of the HFIR calculations that were provided by Dr. Harris of EMT as computer output files. A major part of this review was a detailed evaluation of critical inputs for flaw densities and size distributions. The review verified the correctness and reasonableness of all numerical input numbers used by Dr. Harris.

Based on PNNL's experience and knowledge of past applications of PRAISE, it was concluded that the outputs of the EMT calculations were consistent with the inputs for piping stresses, flaw distributions, and material properties. It was noted that calculated failure probabilities had very small values with cumulative probabilities of large leaks over the life of the plant, which were less than $10^{-10}$. Such small values for failure probabilities are similar to values from past probabilistic fracture mechanics calculations by various organizations (including PNNL) for PWR stainless steel piping systems that like 
HFIR are governed by failures caused by cyclic stresses from operational transients and preexisting fabrication flaws.

Results for the HFIR piping as reported by EMT indicate that failures will occur only if there are large fabrication flaws (e.g., 75 percent of the pipe wall thickness or greater). This trend is consistent with past experience with the PRAISE code. It is noted that the probabilistic fracture mechanics model addresses the statistical randomness in the sizes of the fabrication flaws as well as the randomness in fatigue crack growth rates. As such, small values of calculated failure probabilities for the HFIR piping come from Monte Carlo sampling from tails of statistical distributions, which implies large uncertainties in the calculated values of the piping failure probabilities. The potential impacts of these uncertainties are discussed below.

\section{Stress Inputs}

A review the finite element calculations for piping stresses that provided inputs for the PRAISE code was outside the scope of the PNNL review. However, information provided through ORNL reports and discussions with ORNL staff indicated that the calculations were subject to a high level of prior reviews and were revised to correct inconsistencies in modeling of the HFIR piping. It was also learned that ORNL contracted with an outside organization (EQE) with a national reputation in piping and seismic evaluations for purposes of an independent confirmatory stress analysis of the HFIR piping. These calculations were performed with a finite element program subjected to a rigorous quality assurance program.

PNNL examined the stresses as listed in the ORNL and EMT reports for consistency with values expected from simple/bounding hand calculations. The pressure-induced stresses are readily evaluated and found to be consistent with expected values. Thermal expansion stresses were compared to a bounding value of $24 \mathrm{ksi}$. This value was based on the assumption that the thermal expansion from the HFIR temperature excursion from $70^{\circ} \mathrm{F}$ to $160^{\circ} \mathrm{F}$ was fully constrained. One HFIR location (14-inch pipe) had a thermal expansion stress of about $16.7 \mathrm{ksi}$, or about $66 \%$ of the bounding value. A discussion of this observation with ORNL indicated a relatively low level of flexibility at this piping location, such that the thermal expansion stress was relatively high but still well within limits allowed by the ASME Code. Similarly, the dead weight stress of $13.5 \mathrm{ksi}$ for the 10 -inch piping was also noted as being relatively high, but again well within limits allowed by the ASME Code.

PNNL reviewed the approach (as described in Appendix A of Harris 2001) used to generate equivalent cyclic stress histories. This approach was needed because the PRAISE code was developed for applications to commercial nuclear power plants, and accordingly uses a simplified approach which restricts loading histories to typical pressure and thermal cycles of power reactors. Fortunately the simple Paris power law relationship for fatigue crack growth rates lends itself to adjusting the cyclic stress levels and numbers of cycles in a manner to give the correct interactions of sustained and cyclic stresses (including the effect of $\mathrm{R}=\mathrm{K}_{\min } / \mathrm{K}_{\max }$ ). PNNL in past applications of PRAISE has also used such an approach to adjust stress histories. In summary, the stress history methodology for the HFIR 
calculations was found to be developed in a systematic manner and to provide consistent inputs for the probabilistic fracture mechanics calculations.

\section{Treatment of Thermal Expansion Stresses}

Section 4.1 of the Harris 2001 report states that displacement-controlled stresses from piping thermal expansions were not always included in the calculations of critical crack sizes for sudden and complete pipe severance. Such stresses were neglected for higher toughness welds (non-flux welds) but were included for lower toughness welds (flux welds). In the case of non-flux welds, only the load-controlled stresses (pressure and deadweight) were included in the pipe severance calculations. PNNL reviewed the treatment of displacement-controlled stresses for consistency with accepted practices for evaluating flaws in nuclear piping as approved by the U.S. Nuclear Regulatory Commission and the ASME Section XI Code. It was concluded that the approach used by ORNL and EMT followed practices approved by NRC and ASME. These approaches were developed on the basis of extensive research on pipe fracture consisting of both fracture mechanics calculations and large-scale pipe fracture testing. These criteria for inclusion (or exclusion) of thermal expansion stresses $\left(\mathrm{P}_{\mathrm{e}}\right)$ are outlined in ASME Section XI Appendix C (Evaluation of Flaws in Austenitic Piping) and Appendix C (Evaluation of Flaws in Ferritic Piping).

\section{Treatment of Leak Detection}

The calculations with the PRAISE code accounted for the benefits of leak detection in reducing the probabilities of occurrence of pipe breaks and large disabling leaks. The logic for simulating piping failures was as follows:

(1) At such time as a part-through wall crack is predicted to grow to the depth of the through-wall crack, the existing semi-elliptical part-through crack is assumed to immediately become a through-wall crack with a length equal to the maximum length of the semi-elliptical part-through crack.

(2) A fracture mechanics calculation is performed to determine if the new through-wall crack is stable or unstable with unstable cracks assumed to cause a pipe severance.

(3) Unstable cracks are counted in the Monte-Carlo simulation as contributions to probabilities of both pipe breaks and large disabling leaks.

(4) Leak rates are calculated for the stable cracks and compared with the assumed value of detectable leak rate $(5 \mathrm{gpm})$.

(5) If the calculated leak rate is greater than the detectable rate, it is assumed that the leakage is immediately detected and the reactor is immediately shutdown to permit a repair of the leaking pipe. 
(6) If the leak rate is less than the detectable level, the pipe is assumed to remain in service until the lengthwise growth of the crack causes the leak rate to increase to the detectable level, at which time the leaking piping is assumed to be immediately repaired.

Under these assumptions large disabling leaks will only occur if the initial length of a through-wall cracks exceeds the length of crack corresponding to a disabling leak. This means that a large disabling leak can occur when a crack transitions to become a through-wall crack or not at all. Dr. Harris at EMT was requested to perform a sensitivity calculation to confirm the expected trend of the leak detection model by increasing leak detection threshold from $5 \mathrm{gpm}$ to $50 \mathrm{gpm}$. The two PRAISE runs gave the expected trend of identical probabilities of large disabling leaks.

It should be noted that PRAISE has a basic assumption that the time delay to detect a leaking crack is small relative to the time for a through-wall crack to increase to the size corresponding to a large disabling leak. PNNL concluded this assumption is clearly appropriate for the fatigue crack growth associated with the normal operating transients at HFIR. Further considerations indicated that the assumption of timely leak detection is also reasonable for more rapid crack growth rates associated with high cycle vibrational fatigue.

The trends of the data on vibrational fatigue in the SKI database (Lydell 1999) were discussed during a phone call with Mr. B. Lydell as part of PNNL's review. A detailed interrogation of the current SKI database showed no reported vibrational failures (large leaks) of butt-welded piping in nuclear piping, and specifically none for primary coolant system piping or piping as large as 3-inch diameter.

Furthermore, the maximum of the "large" leak rates in the SKI database was 39 gpm, corresponding to a failure of a 1-inch diameter line. This information indicated that failures reported as ruptures or large leaks while greater than $5 \mathrm{gpm}$ were in all cases much less than the $1500 \mathrm{gpm}$ disabling leak rate of concern to HFIR.

The SKI database on nuclear experience also indicates that vibrational failures are in large measure detected as leakage before the failure develops into a full pipe severance. PNNL also noted from the Updated Final Safety Analysis Report that the primary system is maintained at pressure by two primary pressurizer pumps each with a capacity of $137 \mathrm{gpm}$ and an auxiliary pump with a capacity of $30 \mathrm{gpm}$. These capacities are much greater than the leak rate of $5 \mathrm{gpm}$ assumed in the PRAISE calculations but are much less than the system disabling leak rate of $1500 \mathrm{gpm}$. In the context of vibrational fatigue failures, a growing through-wall crack could result in a rapid increase in leak rate from $5 \mathrm{gpm}$ to $1500 \mathrm{gpm}$ in a time period of less than an hour. However, it appears that the limitations of pump capacities would cause the plant to experience a noticeable decay in system pressure before a $1500 \mathrm{gpm}$ leakage rate is attained. It is therefore reasonable to assume that the trend of the SKI database (vibrational failures have leak rates of $39 \mathrm{gpm}$ or less) is relevant to HFIR.

\section{Selection of Limiting Welds}

PNNL noted that the specific locations for each pipe size used for the PRAISE calculations were selected on the basis of the worst-case nodes that could not be qualified by ORNL for the periodic 
hydrotest. It was initially not clear to PNNL that this procedure would necessarily lead to the selection of the same welds that would also give the highest calculated failure probabilities. The concern was that proof test evaluations would not give the same importance to thermal expansion stresses (relative to seismic stresses), as the probabilistic fracture mechanics model. Discussions with ORNL confirmed that the thermal expansion stresses were properly addressed for all pipe sizes in the selection of welds for the PRAISE calculations. After further evaluation, PNNL concluded that thermal expansion stresses are inherently included in the ORNL hydrotest evaluation for the flux welds (all piping 10 inches and larger). This removed PNNL's initial concerns for the selection of limiting welds for the larger piping. The correct selection of the limiting 3- and 4-inch welds remains based on confidence in ORNL's evaluations, which indicate that these relatively flexible small-diameter lines have relatively small thermal expansion stresses.

Another concern identified by PNNL was that the ORNL evaluations did not specifically address the 3-inch and 18-inch diameter piping, because all welds in this piping were said to be covered by hydrotesting. Concerns with the 18-inch piping were resolved, because the qualification by hydrotesting implies that thermal expansion stress are relatively small. This means that PRAISE calculations would give small failure probabilities $\left(\sim 10^{-18}\right)$ typical of those for the 16- and 20-inch piping rather than those reported for the more highly stressed 14 -inch piping $\left(\sim 10^{-11}\right)$. Concerns for the 3 -inch piping were resolved, because it was learned that the 3-inch piping was addressed by PRAISE calculations that were not reported in the final version of ORNL report. For the 3-inch piping, the calculated probability for a system disabling leak was $\sim 4 \times 10^{-11}$.

\section{Calculation of Failure Frequencies}

The failure probability calculations estimated the probabilities of small leaks (through-wall cracks) and large leaks at sufficient rates (>1500 gpm) to disable the primary coolant system of HFIR and cause core damage. The ORNL approach first calculated failure probabilities for individual girth welds and then calculated an overall failure probability for the primary coolant system. A system level (best estimate) probability of a large system disabling leak of $<10^{-6}$ per year was the criterion used to classify the event as being a "beyond design basis" event. PNNL reviewed the calculated system level probabilities to determine if the probabilities as calculated (including consideration of the uncertainties in the calculations) provide a high level of confidence that the probabilities are less than the goal of $<10^{-6}$ piping failures per year.

The PRAISE calculations gave the largest value for disabling leak for any HFIR weld as $7.7 \times 10^{-10}$. This calculation assumed one fabrication flaw per weld and assumed the occurrence of an earthquake and design basis overpressure event at the 60-year end-of-life. In the present discussion we will not take credit for the low probabilities of seismic and over-pressure events. A bounding probability for fabrication flaws is based on the largest piping in HFIR $(20$-inch $\times 0.60$-inch wall), which gives 0.18 flaws per weld. It was assumed that there are some 50 welds of concern in the piping system and that the operating period of interest is 60 years. The resulting bounding system failure frequency is 
Failure Frequency $<(50$ welds $) \times(0.18$ flaws per weld $) \times(1 / 60$ years $) \times\left(7.7 \times 10^{-10}\right)$

Failure Frequency $<1.0 \times 10^{-10}$ failures per year

PNNL in past work has performed uncertainty analyses that evaluated the uncertainties in failure probabilities calculated by the pc-PRAISE code. These studies have included very small probabilities such as those of the present discussion. At a failure probability of $10^{-10}$ the uncertainty bounds covered 3 to 4 orders of magnitude in each direction from best estimate of median values. Therefore, even an upper bound on the failure frequency accounting for an upper bound on uncertainties would still be consistent with the goal of $<10^{-6}$ failures per year.

It is also useful to note that the very low values of failure probabilities as calculated by PRAISE are consistent with the failure probabilities calculated in other studies that evaluated primary coolant system piping of PWRs. This common trend is expected because of the similarities in materials, designs, operating conditions, and construction standards. HFIR has lower operating pressures and lower operating temperatures relative to PWR plants, which would make for even lower failure probabilities. However, the operational transients and associated cyclic stresses for HFIR are of a different nature than those for PWRs. In this regard, the inputs to the PRAISE calculations were designed to account for these differences, and calculations indicate that the HFIR cyclic stresses (like those for PWRs) result in relatively low rates of fatigue crack growth.

In summary, the approximate or bounding calculations by PNNL, although not following the exact steps or equations used by ORNL, confirm the conclusion that the probabilistic fracture mechanics results demonstrate that failure frequencies for HFIR piping are much less than $10^{-6}$.

\section{Sensitivity Calculations}

Sensitivity calculations were performed by EMT to address some concerns identified by PNNL and Brookhaven National Laboratory staff during the meeting held at ORNL on August 2, 2001. These sensitivity calculations covered some of the same issues as past uncertainty calculations performed by PNNL on an NRC-funded research project. The sensitivity calculations supplement the prior PNNL studies by addressing other issues. The EMT calculations included effects of residual stresses, truncation of the Monte-Carlo simulation, an alternative/updated curve for fatigue crack growth rates, vibratory stresses, and the parameters used for the leak rate calculations.

- Residual Stresses - Residual stresses can be due to the heat inputs applied during welding processes or may originate during the fit-up of the piping during construction. EMT performed PRAISE calculations for several assumed distributions of residual stresses. Tensile residual stresses increased the mean stress level (or R-ratio) that enters into the calculations of fatigue crack growth. The most conservative assumption was that of a 30-ksi stress distributed uniformly through the thickness of the pipe wall. For this bounding case, the probability of disabling leak increased by about a factor of 10 from $7 \times 10^{-13}$ to $5 \times 10^{-12}$. This change is too small to change the essential conclusion that failure frequencies are much less than $10^{-6}$ per year. 
- Monte Carlo Truncation - The PRAISE calculations by EMT used a minimal number of trials needed to achieve 10 failures per cell of the stratified sample space used to describe the depths and lengths of the initial fabrication flaws. This number of trials was considered by EMT to be adequate to achieve a reasonable level of accuracy. A sensitivity study was requested to increase the base line of 10 failures to 100 and then 2000. The study gave a change in calculated failure probabilities of less than a factor of 2. This demonstrated that a more conservative limit on the Monte Carlo sampling truncation would have little impact on meeting the failure probability criteria of $<10^{-6}$ per year.

- Fatigue Crack Growth Rates - The probabilistic correlation for fatigue crack growth rates used by PRAISE was developed during the early 1980s. Subsequently, more data from fatigue crack growth tests have become available and a correlation of this expanded set of data has been developed for use in the ASME Section XI Code. Plots were developed by EMT to compare crack growth rates of the more recent code equation with the correlation of PRAISE code. It should be noted that no probabilistic calculations were performed with the PRAISE code. Nevertheless, the comparison of crack growth rates showed that the PRAISE correlation would tend to predict somewhat higher crack growths than the more recent correlation. Therefore, from the standpoint of crack growth rates, it is expected that piping failure probabilities will tend to be overestimated by the PRAISE code.

- Leak Rate Calculations - PRAISE calculations were performed to evaluate the effect of uncertainties in the pathway loss coefficient $(e)$ on calculated failure probabilities. A smaller value for $e$ means that shorter cracks will result in the critical leak rate of $1,500 \mathrm{gpm}$, with a corresponding increase in calculated failure probabilities. A decrease in $e$ from 6 to 3 increased the failure probability by a factor of about 2 , which is a small change in the present context.

- Vibratory Stresses - EMT was requested to perform a set of PRAISE calculations to study the potential effect of vibrational stresses on piping failure probabilities. These calculations supplemented other calculations by PNNL that had the same objective. The inputs for vibrational stresses to both the EMT and PNNL calculations were intended to be very conservative. The objective was to establish which of the larger HFIR pipe sizes could be considered beyond any concern for vibrational stresses.

The guidelines of draft report NUREG-1661 were used to select bounding inputs for vibrational stresses. These inputs conservatively assumed that (1) a significant source of vibrational stress exists at the piping location of concern, and (2) the resulting level of vibrational stress was at the bounding levels recommended in NUREG-1661 for use in developing risk-informed inservice inspection programs.

Figure 1 presents results of sensitivity calculations performed by PNNL. A deterministic threshold value for the $\Delta \mathrm{K}$ was assigned at 4.0-ksi $\sqrt{ }$ inch. The crack depth distribution and the number of flaws per weld were the same as used in the EMT PRAISE calculations. PNNL conservatively assumed that all flaws were very long (large aspect ratio). The calculations in effect predicted the probability of a weld having a flaw of sufficient depth to exceed $\Delta \mathrm{K}_{\mathrm{th}}$ for the specified vibrational stress levels. Figure 1 indicates that pipe sizes of about 6 inches or greater will have probabilities less than $10^{-6}$. From these 
calculations PNNL concluded that only the 3- and 4-inch piping at HFIR will present any concern for vibrational stresses. Figure 1 indicates that the smaller diameter piping could have probabilities of small leaks in the range of $10^{-3}$ to $10^{-2}$ with probabilities for larger leaks of (1500 gpm) being much smaller.

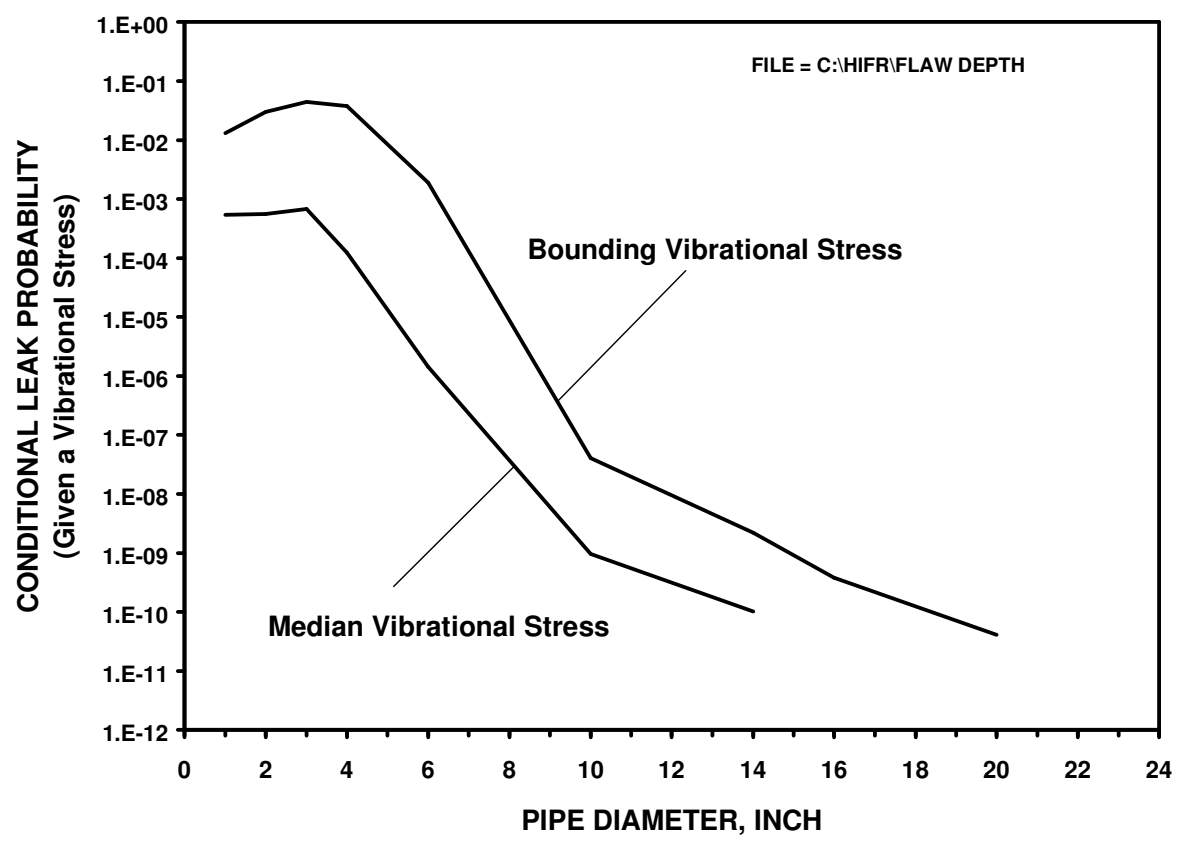

Figure 1. Estimates of Small Leak Probabilities Based on Guidance of NUREG-1661

Probabilistic calculations were performed by EMT with results summarized by Table 4 of their report to ORNL. Probabilities for small leaks for 3- and 4-inch piping were consistent with the probabilities estimated by PNNL. The EMT results also included PRAISE predictions for system-disabling leaks (1500 gpm or greater) having values in the range of $10^{-12}$ to $10^{-8}$. However, PNNL discussed these results with EMT. It was concluded that limitations in the PRAISE treatments of vibrational fatigue and leak detection make these predictions of questionable value. Specifically, PRAISE does not in the case of vibrational stresses account for fatigue crack growth once a part-through-wall crack transitions to become a leaking through-wall crack. In addition, PRAISE assumes that a leak rate greater than $5 \mathrm{gpm}$ is immediately detected, and does not account for the rapid increase in crack lengths that could occur during the short time period of a few hours needed for the plant operational staff to diagnose the various control room indications that a leak has developed.

The guidance of NUREG-1661 permits a probability to be estimated for the occurrence of the bounding vibrational stress. Typical applications of the risk-informed procedures have assigned this probability to be zero, unless clearly justified by adverse conditions that apply for a specific piping location. Examples would be a history of cavitation or flow-induced vibration, presence of fatiguesensitive socket welds, poorly supported cantilevered small diameter piping, a history of pipe failures, observations of vibrational sources from rotating equipment, etc. 
In summary, the sensitivity calculations for vibrational fatigue were in some respects inconclusive. For pipe sizes 6 inches and greater the results show that vibrational stresses should make insignificant contribution to piping failure probabilities relative to the $10^{-6}$ failure frequency. However, smaller piping (3- and 4-inch diameter) needs to be addressed on a case-by-case basis, by demonstrating that sources of vibrational stresses and potential levels of vibrational stress are insignificant. Factors as they apply to small diameter HFIR piping are discussed in a later section of the present report.

\section{Uncertainties and Conservatisms in PRAISE Calculations}

There are many uncertainties related to both the inputs to the PRAISE code and perhaps more importantly the formulation of the fracture mechanics model itself. These uncertainties can either increase or decrease the calculated failure probabilities. Some of these uncertainties, including factors that could increase the failure probabilities, were addressed by sensitivity calculations as described above. In contrast, there are other modeling assumptions and treatments of input parameters that could decrease the failure probabilities that were not addressed by the sensitivity calculations. The discussion below identifies a number of such conservative assumptions. Also discussed is a systematic quantification of uncertainties in the PRAISE calculations that was performed by PNNL at the request of NRC staff.

\section{Evaluation of Uncertainties in Probabilistic Calculations}

PNNL on a past NRC project performed a systematic uncertainty analyses that evaluated the uncertainties in failure probabilities as calculated by the PRAISE code (Khaleel and Simonen 1999). This study is relevant to the present review because it concerned fatigue failures due to fabrication flaws and covered the very small failure probabilities of concern to HFIR piping.

Figures 2 through 4 show results from the PNNL uncertainty analysis. These calculations described important input parameters to PRAISE (such as the number and sizes of flaws per weld) in terms of statistical distributions rather than as point estimates. As indicated in Figures 2 through 4, the uncertainty calculations gave a distribution of possible values for leak and break probabilities rather than as a single best estimate value. Mean and median values were then calculated from these distributions for comparison with best estimate values. The upper and lower bounds of Figure 3 correspond to approximately the $1^{\text {st }}$ and $99^{\text {th }}$ percentiles of the range of calculated failure probabilities. It is seen that the uncertainties become larger (range between bounding curves) as the failure probabilities become smaller. The median values tend to be relatively close to the best estimate values, whereas the mean values of the uncertainty distributions are significantly larger than the best estimate values.

At a failure probability of $10^{-10}$, the uncertainty bounds covered 3 to 4 orders of magnitude in each direction from the best estimate values. Therefore, even an upper bound on the failure frequency accounting for an upper bound on uncertainties would still be consistent with the goal of $<10^{-6}$ failures 


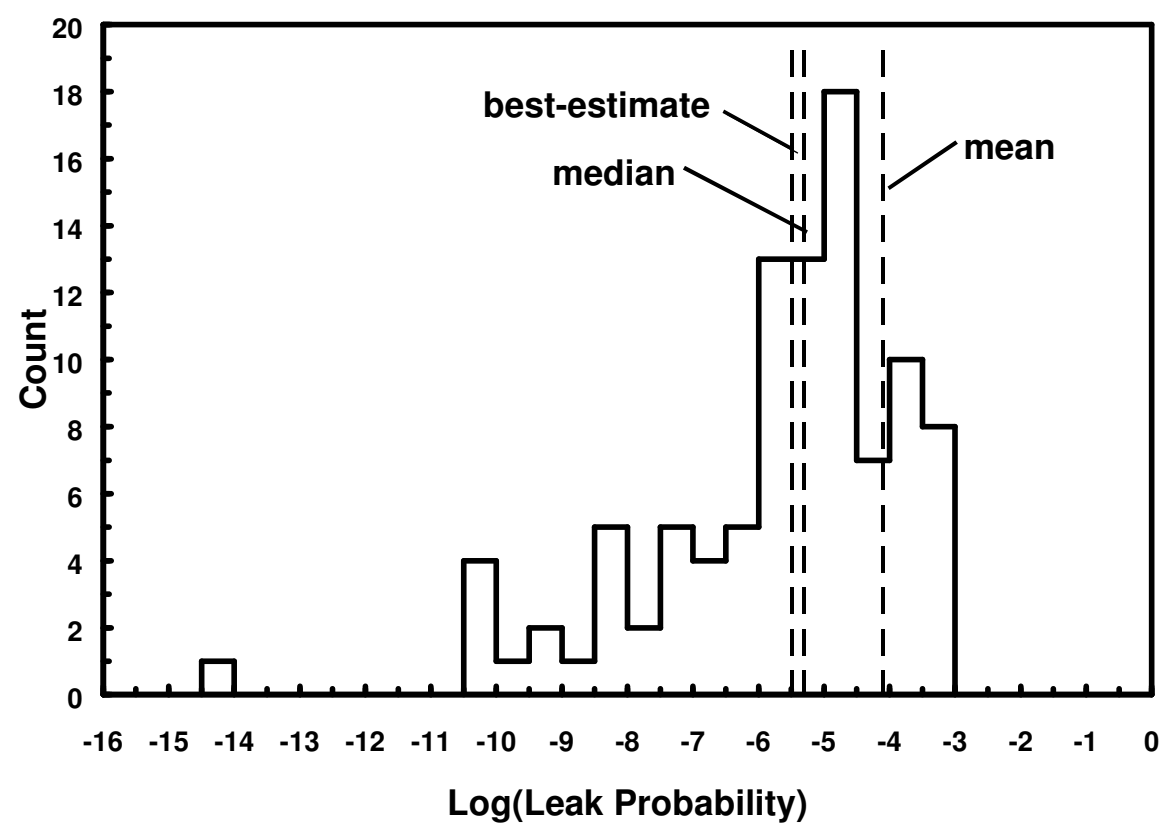

Figure 2. Histogram for Probability of Failure Calculated by PRAISE

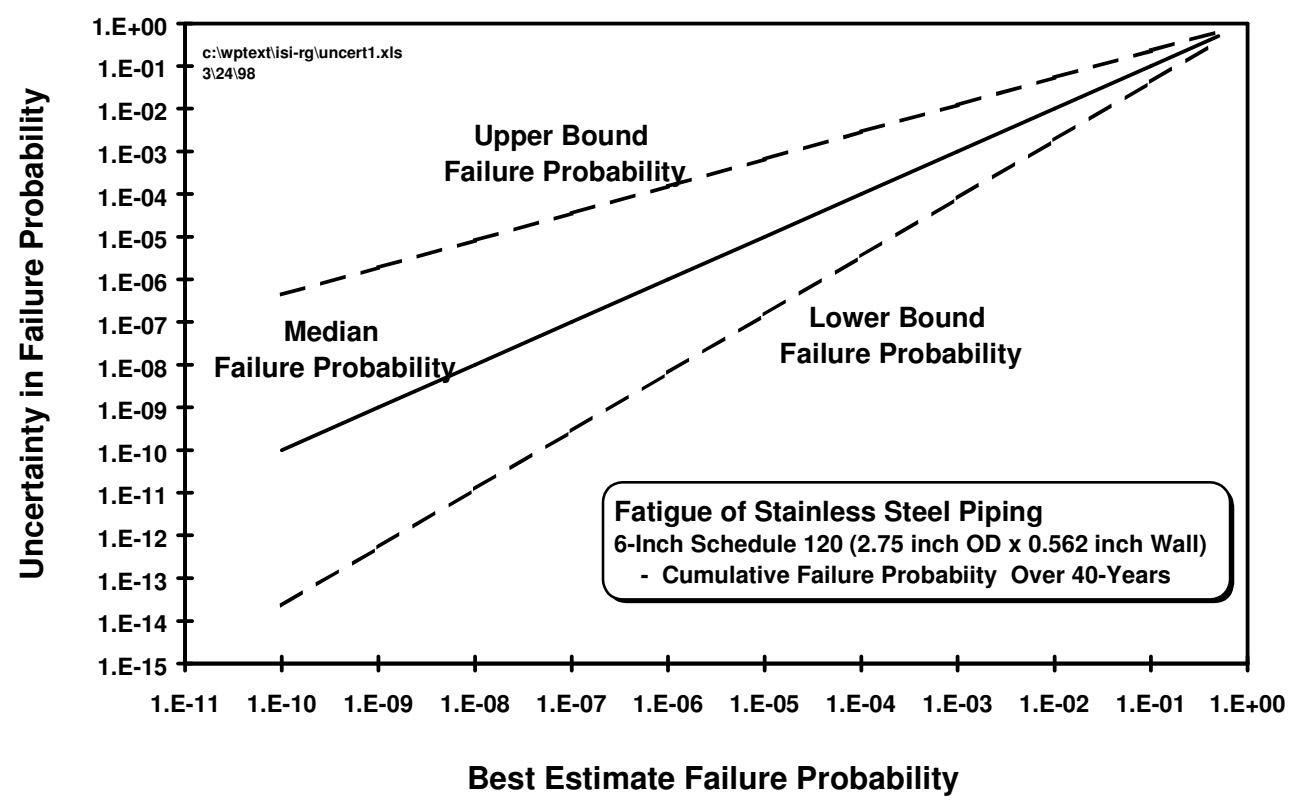

Figure 3. Upper and Lower Bounds of Leak and Break Probabilities from Uncertainty Analyses 


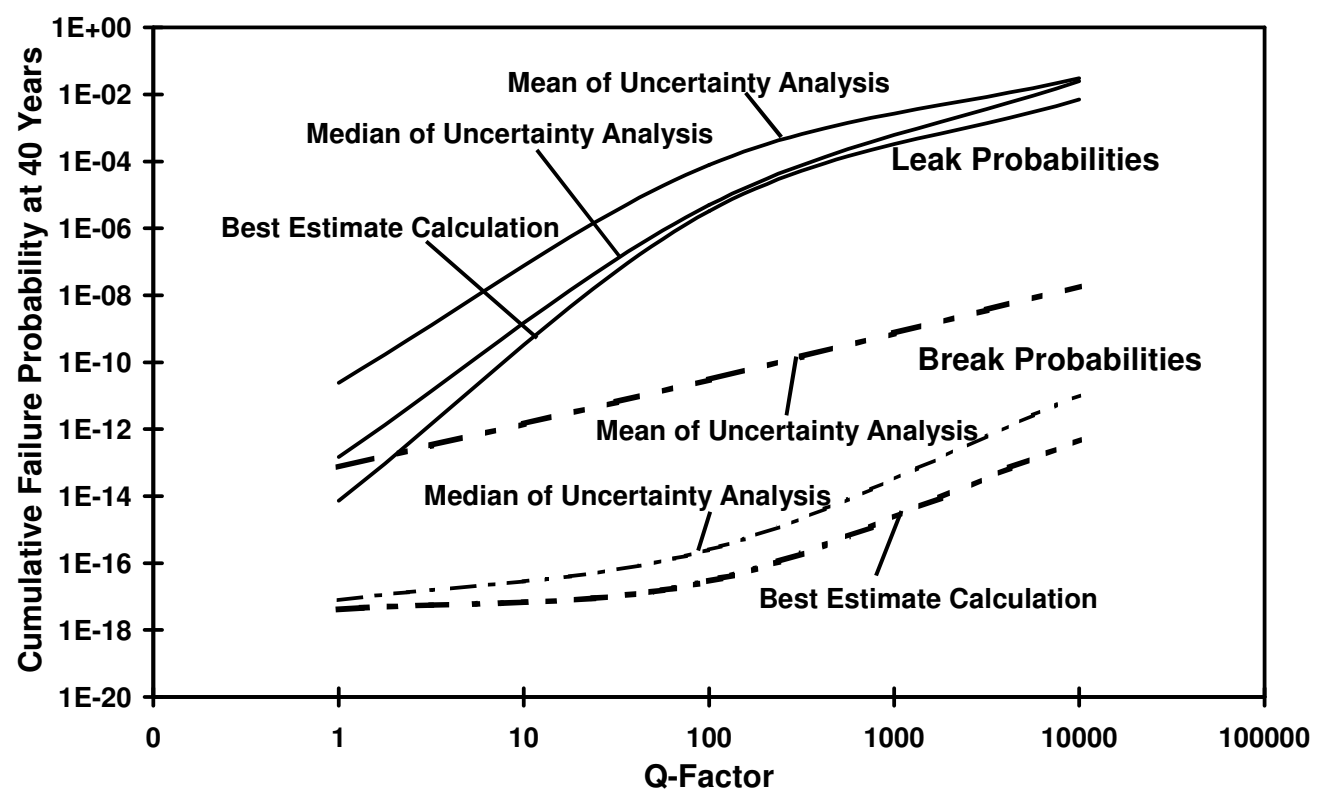

Figure 4. Probabilities from Uncertainty Analyses Compared to Best Estimate Calculations

per year. However, it is inappropriate to use an upper bound value in the present HFIR evaluation. The stated criteria for acceptable failure probabilities was in terms of a best estimate, with any considerations of uncertainties encompassed in the $<10^{-6}$ acceptance standard. Other risk evaluations state the acceptance standards in terms of a mean value for failure probability rather than a best estimate value. Figure 4 indicates (failure probability of about $10^{-10}$ ) that the mean value of failure probability would be a factor of 10 to 100 greater than the best estimate value. This would lead to an upwards adjustment of the best estimate HFIR failure probability of $10^{-10}$ to $10^{-8}$ if the acceptance standard were to be stated in terms of a mean value of failure probability.

\section{Conservatisms in PRAISE Fracture Mechanics Model}

The sensitivity calculations addressed concerns with potentially optimistic assumptions in the fracture mechanics model and inputs to the calculations that could increase the failure probabilities from the PRAISE code. We now list a number of conservative aspects of the calculations that cannot readily be quantified but nevertheless collectively result in conservative estimates for failure probabilities:

(1) Random fabrication flaws in welds are assumed to occur at the same circumferential locations as the circumferential location of maximum stress resulting from pressure, dead weight, thermal expansion stress, and seismic loading (potentially a factor of 2 to 5 effect on failure probability).

(2) Failure probabilities are calculated with the bounding stress levels for each pipe size, and are then assumed to apply to all welds of concern for this pipe size (potentially a factor of 2 to 5 effect on system failure probability). 
(3) The stresses on the pipe welds dead weight, thermal expansion, and seismic loading are added together. In some cases a compressive stress from one source may cancel a tensile stress from another source. In other cases the maximum tension from one source could be at the top of the pipe cross section, whereas the tension stress from another source could be at flank location offset at 90 degrees (potentially a factor of 2 to 5 effect on failure probability).

(4) No credit is taken for the ultrasonic inservice inspections of welds, both in eliminating individual degraded welds before they fail, and in identifying and correcting unexpected operational conditions to prevent additional occurrences of cracking (potential factor of 2 to 5 effect on failure probability).

(5) The PRAISE calculations take no credit for the very sensitive ability to detect leakage ( $<5 \mathrm{gpm})$ by visual means during the routine pressure tests at reactor startup performed at intervals as short as once per month.

(6) The fracture mechanics model of PRAISE assumes that growing part-through fatigue cracks immediately become a full though-wall cracks with a length equal to the maximum length of the original part-through crack. Long part-through cracks go suddenly from zero leakage to the leak rate for the full-length through-wall crack. In contrast, experience shows that through-wall cracks start with only a short length penetrating at the outer surface of the pipe. This length then gradually increases with an associated increase in leakage rate. The pressure tests at HFIR (performed as frequently as once per month) that would provide opportunities for the visual detection of low levels of leakage, which would greatly decrease the subsequent likelihood of large leaks.

(7) The crack growth rate correlation used in the PRAISE calculations was derived for PWR conditions and are based in part on crack growth rate data from water environment tests for PWR reactor water conditions. Therefore, the crack growth rates may be conservative for the temperatures and environment of HFIR piping.

In summary, we have listed a number of unquantified conservatisms in the PRAISE calculations that collectively could readily account for overestimating piping failure probabilities by perhaps two orders of magnitude or more. The ORNL evaluation did not consider these sources conservatisms but, on the other hand, did address some potential factors from the EMT sensitivity calculations that increased estimated failure probabilities.

\section{Review of Alternative Failure Mechanisms}

The PNNL review has also evaluated the possibility that the governing failure mechanism could be other than the fatigue crack growth mechanism addressed by the PRAISE calculations. A review was performed by PNNL independently of a similar review by ORNL. PNNL came to the same conclusion that there is no reason to believe that failure mechanisms not addressed by the PRAISE calculations could cause the failure frequency (greater than 1500 gpm leak) to be greater than $10^{-6}$. 
It was recognized that there is no evidence of leaks or service-induced cracking during the many years of operational experience at HFIR. However, the PNNL evaluation addressed the potential for future occurrences of failure mechanisms such as stress corrosion cracking, thermal fatigue, flow-assisted corrosion, or vibrational fatigue that have been observed at commercial nuclear power plants. Occurrences of such mechanisms at commercial nuclear power plants have resulted in most cases in small leaks and much less frequently in pipe rupture events.

Section XI of the ASME Code currently has a methodology (Code Case N-578-1 Risk-Informed Requirements for Class 1, 2, or 3 Piping Method B, Section XI, Division 1) to identify failure mechanisms that are relevant to specific piping locations. This methodology accounts for factors related to the materials and operating conditions. The following degradation mechanisms are addressed by Table 1-1 of this N-578-1:

- Thermal Fatigue - HFIR operates at low temperatures with inlet and outlet temperatures of $120^{\circ} \mathrm{F}$ and $160^{\circ} \mathrm{F}$, respectively, which offers little opportunity for significant thermal fatigue type stresses. The ASME Code Case considers thermal fatigue to be relevant if there is a potential for the mixing of hot and cold fluids with temperature differences $>50^{\circ} \mathrm{F}$ such as due to leakage past flow control valves or from turbulent penetration of a branch connection containing a hot flowing fluid. None of these conditions are known to exist at HFIR. In the case of rapid changes in temperatures due to the initiation of cold fluid injection, the Code Case is concerned with thermal fatigue of stainless steels only if the temperature differences exceed $200^{\circ} \mathrm{F}$. This precludes thermal fatigue for the conditions that exist at HFIR.

- Stress Corrosion Cracking - Stainless steel piping is considered susceptible to IGSCC for BWR systems and is to be evaluated per NRC Generic Latter 88-01. The BWR conditions do not apply to HFIR because of relatively low operating temperatures and more favorable water chemistries. At operating temperatures $<200^{\circ} \mathrm{F}$ stress corrosion cracking is of concern only if water chemistries have contaminants such as chlorides and fluorides. The Code Case considers SCC to be of concern at temperatures as low as $150^{\circ} \mathrm{F}$ if the outside surface of the piping is exposed to wetting by chloride bearing environments such as brackish water. Cracking of Inconel piping and of welds with Inconel buttering is also of concern, but only for temperatures well above the HFIR operating temperatures. With relatively low operating temperatures and the control of both water chemistries and external environments as practiced at HFIR, the ASME Code Case would not consider stress corrosion cracking to be relevant to HFIR piping.

- Localized Corrosion - The Code Case addresses degradation mechanisms such as microbiologically induced corrosion (MIC), pitting (PIT), and crevice corrosion (CC). MIC is not relevant to HFIR coolant piping because the adverse water chemistries such as present in raw water systems are not present. PIT is likewise not relevant from consideration of the high purity of the water at HFIR. For $\mathrm{CC}$ to occur there must be design features to produce crevices, water temperatures $>150^{\circ} \mathrm{F}$ and adverse water chemistries, which are factors not present at HFIR. 
- Wall Thinning - Erosion-cavitation can occur at the lower temperatures of HFIR operation, but the flow velocities must be relatively high ( $>30$ feet/second) with the potential occurrence of cavitation at locations such as throttling or pressure-reducing valves or orifices. No such conditions are known to exist for the HFIR piping.

- Water Hammer - This mechanism requires unusual conditions such as fluid voiding and relief valves discharge that are not known to exist at HFIR.

- Vibrational Fatigue - The Code Case does not list vibrational fatigue, but was identified in PNNL's review as a potential mechanism for HFIR, because there are no clear differences between HFIR and commercial nuclear power plants in terms of piping materials, piping design, and operating environments. PNNL addressed vibrational fatigue in detail as discussed in the next section of the present report. This mechanism was eliminated from consideration after ORNL provided additional details of the HFIR piping design and operational practices. It should be noted that vibrational stresses have been the cause of many piping failures at commercial plants, and for small bore piping in particular. However, PNNL is not aware of specific cases of vibrational failures for piping with diameters as large as 3 to 4 inches, although such failures are reported in a database on piping failures available to PNNL staff.

In summary, the only alternative failure mechanism of concern is that of vibrational fatigue. The following section addresses this mechanism in detail and concludes, based on plant-specific factors for HFIR, that vibrational fatigue should not impact the essential conclusion that large leak frequencies should be $<10^{-6}$ per year.

\section{Potential for Vibrational Stresses}

This section reviews factors relevant to HFIR that govern the potential for vibrational fatigue failures. It is concluded that such failures should be of sufficiently low probability that this failure

mechanism will not impact the conclusion that failure frequencies for HFIR piping are less than $<10^{-6}$ per year.

\section{Data on Vibrational Fatigue Failures at Commercial Nuclear Power Plants}

Data on piping failures at commercial nuclear power plants (Simonen and Gosselin 2000) show that vibrational fatigue (VF) is a significant contributor to piping failures as indicated by Figures 5 and 6 . Failures are much more common in small diameter piping (diameter $<2$ inch) than for larger piping with few failures in piping with diameters greater than 2 to 3 inches. Failures of small-bore piping are very often associated with socket-welded connections. 


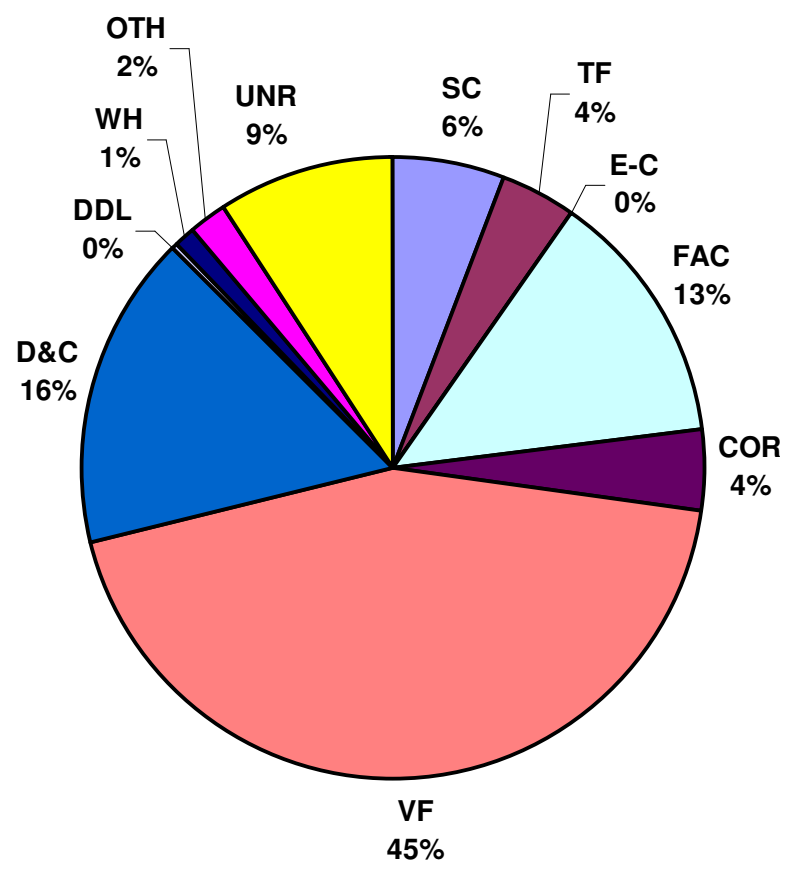

Figure 5. Service Failures in Small Bore Piping ( $<2$ inch NPS)

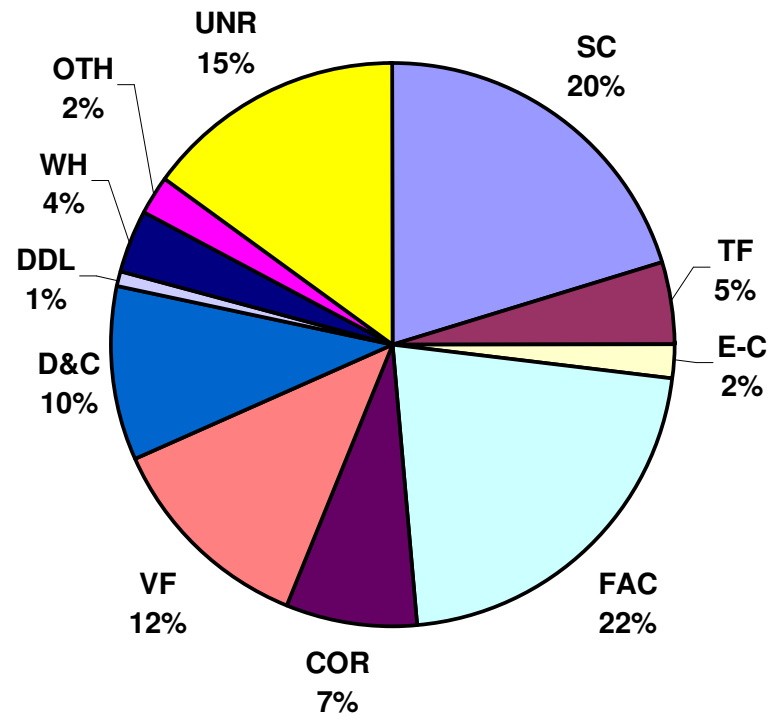

Figure 6. Service Failures in Large Bore Piping ( $>2$ inch NPS)

Another important trend (shown by Figure 6) is that vibrational fatigue failures are most frequent during the early years of plant operation. The failure rates then decrease as plants correct design problems and identify and mitigate sources of vibrational stress. Therefore, it is likely that piping locations at HFIR with any potential for vibrational fatigue would likely have already failed early in the 
life of the plant. Nevertheless, vibrational failures have continued to occur at commercial power plants (but at much lower rates) during later years of operation. Failures later in life can be associated with the development of new sources of vibrational stresses (bearings in rotating equipment fail) or due to vibrations that occur only during brief operational periods (plant startup or during testing of equipment) such that many years of operation are needed to accumulate a sufficient number of cumulative cycles $\left(10^{5}\right.$ to $\left.10^{6}\right)$ to cause a failure by high cycle fatigue.

A database from an ongoing world-wide data search for piping failures (Bush et al. 1996; Lydell 1999) shows 85 leaks and 4 pipe rupture events for piping $>2$-inch diameter. Assuming that this data base covers 4000 years of reactor operation, we can estimate a failure frequency of $4 / 4,000=10^{-3}$ per year. The reported failures cover a large population of plants, piping designs, and operating conditions, which in most instances would not be relevant to HFIR. A plant-specific evaluation for vibrational failure considering the HFIR plant-specific conditions can justify much lower values for failure frequencies for the reasons discussed below.

The ORNL report cites a report on initiating events (INNEL 1999) that shows no vibrational fatigue failures for piping 3-inch diameter or greater. This conclusion would appear to be inconsistent with the SKI database. Because PNNL did not have access to the cited INNEL report, the apparently conflicting information could not be reconciled. However, it is likely that the INNEL report confined the definition of initiating events to larger leaks (or pipe breaks), and may only have considered failures that impacted the primary coolant system. The INNEL database may also have been limited to experience in the United States, whereas the SKI data also covered overseas plants.

It could not be determined if any of the 4 pipe ruptures in the SKI data were for piping as large as 3 inches or if the failures were for piping in the range of 2 to 3 inch. PNNL staff are also aware of other difficulties in the application of databases caused by the incorrect reporting of details associated with failure events. It is common for vibrational failures to occur at a location where a small-diameter piping connects to a large-diameter line. In such cases, a failure in small-bore pipe is often incorrectly reported as being in the larger-diameter line. In other cases, the failed pipe is repaired without a detailed root cause analysis. In such cases, a failure may be reported in a database as vibrational fatigue, where a correct evaluation would attribute the failure to another cause such as thermal fatigue.

\section{Plant-Specific Vibrational Factors for HFIR Piping}

Although a conservative estimate of a failure frequency (large leak) of $10^{-3}$ per year could be assigned for vibrational fatigue of small-diameter HFIR piping ( 3 to 4 inch), such a high failure frequency is not a reasonable estimate for HFIR piping for the following reasons:

(1) HFIR has operated for some 35 years without any vibrational fatigue failures (even small leaks) and the industry trends show that it is even more unlikely that failures will occur during a future period of operation. 
(2) The HFIR piping of concern has diameters of 3 and 4 inches, which is a size range for which vibrational failures are rarely if ever experienced and larger than the $>2$-inch cutoff of the SKI database.

(3) There are no socket-type welds in the HFIR piping of concern.

(4) HFIR has instrumentation on coolant pumps to monitor for displacement (with an automatic shutdown feature), which will minimize the most likely source of vibrational stresses.

(5) Plant operational staff have access to the HFIR piping prior to each period of reactor operation and have opportunities to observe any unusual conditions that would indicate the presence of vibrational stresses.

(6) The piping designs at HFIR have been extensively reviewed and analyzed, including walkdowns of the piping by a leading piping design organization to identify features that would make pipe runs susceptible to vibration.

The following section describes how these factors would collectively contribute to a very low probability of vibrational failure.

\section{A Semi-Quantitative Evaluation of HFIR Piping}

Most of the failures in the SKI database (diameters $>2$ inch) are most likely for piping only somewhat greater than 2-inch diameter. It is not known if any of these reported failures corresponded to piping even as large as 3-inch diameter. We will assume for the present discussion that only 1 of the 4 failures was for piping 3 -inch or greater, which reduces the failure probability by a factor of $1 / 4$.

The data on service experience shows that vibrational failures are more common early in the life of a plant (see Figure 7) as vibrational problems are discovered and corrected. Nevertheless, vibrational failures have continued to occur at lower rates after the initial years of plant operation. The nominal failure frequency of $10^{-3}$ per year as cited above would be unrepresentative of an older plant such as HFIR. Furthermore, it is also noted that no vibrational failures have ever been reported at HFIR even for small leaks in the smallest diameter piping, which is an indication that there are few if any significant vibrational sources. Such indications of favorable past operational experience provide justification for estimating failure probabilities for HFIR that are significantly less than for commercial power reactors. We will assume for the present discussion a reduction factor of $1 / 10$ for periods of future operation.

The failures in the database cover all systems in commercial power plants (feedwater systems, etc.), and not only the piping of the primary coolant system. Therefore, the number of piping welds per plant at risk as addressed by the database is much higher than the piping of concern to the HFIR evaluation. We will assume for the present discussion a factor of 5 for the number of welds at risk, which reduces the failure probability by a factor of $1 / 5$. 


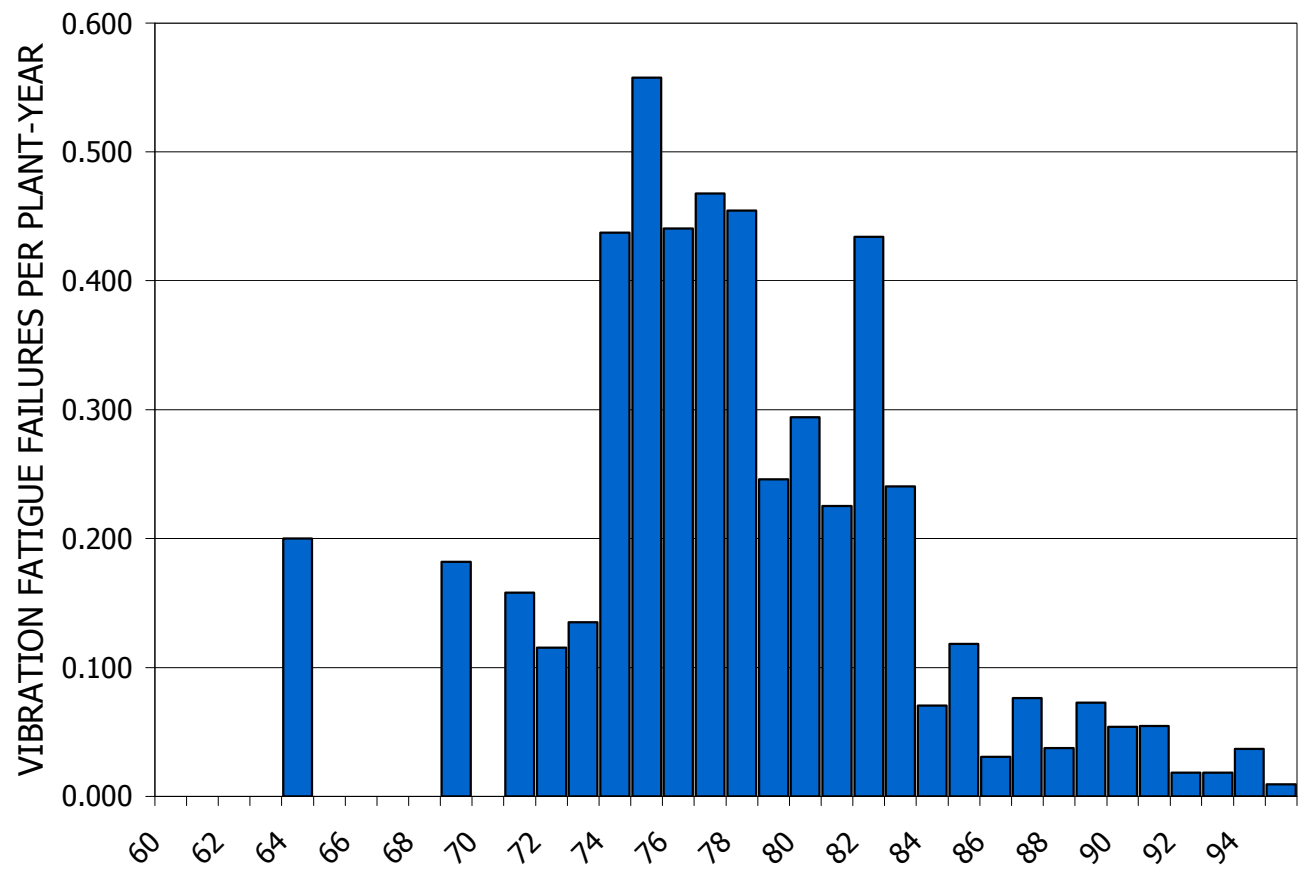

Figure 7. Vibrational Fatigue Failures Showing Decrease In Failure Rate as Plants Become Older

It is known that the operating conditions (vibration sources such as from flow cavitation) are more severe for the piping addressed by the SKI database than for the HFIR piping of interest. We will assume for the present discussion a factor of 5 in terms of failure probabilities, which reduces the failure probability by a factor of $1 / 5$.

HFIR is reported to have no failure-prone socket-type welds. We will assume for the present discussion that a factor of 10 applies in terms of failure probabilities for the HFIR weld configurations relative to those addressed by the failures reported in the database, which reduces the failure probability by a factor of $1 / 10$.

Combining the above factors and applying the combined factor to the failure frequency of $10^{-3}$ per year gives

$$
\begin{aligned}
\text { Failure Frequency } & \cong(1 / 4) \times(1 / 10) \times(1 / 5) \times(1 / 5) \times(1 / 10) \times\left(10^{-3} \text { per year }\right) \\
& \cong 1 \times 10^{-7} \text { per year }
\end{aligned}
$$

The above calculation is intended to argue why the failure frequency for the 3- to 4-inch diameter lines at HFIR are likely to be less than $1 \times 10^{-7}$ per year. Nevertheless, the calculation shows how various plantspecific factors can reduce the expected failure probabilities to negligible levels. It is concluded that HFIR piping should have frequencies of vibrational fatigue failures that are very small relative to generic failure rates for reactor piping. 


\section{Exploratory Calculations with PRAISE}

A previous section of the present report describes sensitivity calculations for vibrational fatigue with PRAISE. These calculations show that an application of NRC guidelines for the treatment of vibrational fatigue gives failure rates for piping $>6$ inch that are negligible even for conservative bounding inputs for vibrational stress levels. These same guidelines can also be applied to 3- and 4-inch piping to allow vibrational stresses to be neglected for calculations of failure probabilities. However, a review of the plant-specific factors is needed to justify the use of inputs less conservative than the bounding values recommended in the NRC guidelines.

\section{Conclusions on Potential for Vibrational Fatigue}

In summary, the PNNL review comes to the following conclusions relative to the potential for vibrational fatigue failures in HFIR piping:

(1) Large-diameter piping (6 inches and greater) is estimated to have negligible failure frequencies due to high cyclic vibrational stresses.

(2) Small-diameter piping (diameters of 3-4 inches) should also have very low failure frequencies from high cyclic vibrational stresses. It is difficult to quantify a failure rate for this piping. However, the NRC guidelines for estimating failure probabilities for risk-informed inservice inspection programs would justify the exclusion of vibrational fatigue as a relevant failure mechanism for the smaller diameter HFIR piping.

(3) Vibrational failures may be the most likely potential cause of failure for HFIR piping, but only because (1) other sources of cyclic stress from plant operational transients give such very low failure probabilities, and (2) all other potential failure mechanisms such as stress corrosion cracking, thermal fatigue, and flow-assisted corrosion are not credible contributors to piping failures.

(4) There are measures in place at HFIR to assure and to gain confidence that probabilities of vibrational failure are maintained at low levels including monitoring and measurements of vibrational stresses, monitoring of potential sources of vibrational loadings such as pumps, and procedures for detecting leakage both during periods of operation and during pressure tests prior to periods of operation.

\section{Conclusions and Recommendations}

PNNL has reviewed documents from ORNL that present the technical bases for the conclusion that the loss-of-coolant accident at HFIR has a frequency of occurrence less than $1 \times 10^{-6}$ per year for piping 3 inches and greater. PNNL reviewed the computational methods and input parameters for the PRAISE code that was used for probabilistic fracture mechanics calculations. Another part of PNNL's evaluation 
addressed potential failure mechanisms not explicitly addressed by the PRAISE calculations, with a specific focus on the potential for high cycle vibrational fatigue.

PNNL endorses the conclusion that the expected annual frequency of large leaks ( $>1500 \mathrm{gpm})$ for HFIR piping is less than $10^{-6}$ per year. A detailed evaluation of factors relevant to HFIR piping concluded that vibrational fatigue will not increase the failure frequency beyond this limit. These conclusions are based on the following considerations:

(1) A review of the probabilistic fracture mechanics calculations performed with the PRAISE code. These calculations predict failure frequencies that are much less than $10^{-6}$ per year.

(2) A comparison of the materials and design of the HFIR piping with similar piping systems at commercial nuclear power plants which operate under conditions of temperature and pressures more severe than those for HFIR. These piping systems have exhibited a high level of structural reliability for which the failure frequencies have been characterized as less than $10^{-6}$ per year.

(3) The lack of any evidence of active degradation mechanisms in the form of cracking or leaks during the many years that HFIR has operated.

(4) The reportedly high construction standards used in the fabrication of HFIR piping along with ORNL's subsequent ultrasonic inspections of HFIR welds that have not shown evidence of fabrication flaws of significant size.

(5) The many measures now in place at HFIR that will reduce the potential for piping failures, including (a) hydrotesting of the primary pressure boundary, (b) vibration monitoring for sources of high-cycle fatigue stresses, (c) ultrasonic inspections of welds, (d) the frequent visual inspections for evidence of small levels of leak as part of pressure tests performed before each operational interval, and (e) the potential to detect larger leaks during periods of plant operation.

\section{References}

American Society of Mechanical Engineers. 1998. ASME Boiler and Pressure Vessel Code - Section XI Rules for Inservice Inspection of Nuclear Power Plant Components.

American Society of Mechanical Engineers. 1998. Code Case N-578-1 Risk-Informed Requirements for Class 1, 2 or 3 Piping, Method B Section XI, Division 1.

Bishop, B.A. 1997. “An Updated Structural Reliability Model for Piping Risk Informed ISI,” ASME PVP-Vol. 346, Fatigue and Fracture, pp. 245-252. 
Bruckner-Foit, A., T. Schmidt, and J. Theodoropoulos. 1989. "A Comparison of the PRAISE Code and the Paris Code for the Evaluation of the Failure Probability of Crack-Containing Components," Nuclear Engineering and Design, Vol. 110, pp. 395-411.

Bush, S.H., M.J. Do, A.L. Slavich, and A.D. Chockie. 1996. Piping Failures in United States Nuclear Power Plants: 1961-1995, SKI Report 96:20.

Cherverton, R.D. 2001. Probability of Failure of the HFIR Primary Piping, RDC/ORNL/RRD/LTR01-1. Prepared by Delta-21 Resources for Oak Ridge National Laboratory, Oak Ridge, Tennessee.

Deardorf, A.F., and J.K Smith. 1994. Evaluation of Conservatisms and Environmental Effects in ASME Code, Section III, Class 1 Fatigue Analysis, SAND94-0187. Prepared by Structural Integrity Associates for Sandia National Laboratory.

Harris, D.O., E.Y. Lim, and D.D. Dedhia. 1981. Probability of Pipe Fracture in the Primary Coolant Loop of a PWR Plant, Vol. 5: Probabilistic Fracture Mechanics Analysis, NUREG/CR-2189, U.S. Nuclear Regulatory Commission, Washington, D.C.

Harris, D.O., D.D. Dedhia, E.D. Eason, and S.D. Patterson. 1986. Probability of Failure in BWR Reactor Coolant Piping: Probabilistic Treatment of Stress Corrosion Cracking in 304 and 316NG BWR Piping Weldments, NUREG/CR-4792, Vol. 3, U.S. Nuclear Regulatory Commission, Washington, D.C.

Harris, D.O., E.D. Eason, J.M. Thomas, C.J. Bianca, and L.D. Slater. 1987. "NASCRAC a Computer Code for Fracture Mechanics Analysis of Crack Growth," AIAA-87-0847-CP, prepared for the AIAA/ASME/ASCE $28^{\text {th }}$ Structures, Structural Dynamics and Materials Conference, Monterey, California, April 6-8, 1987.

Harris, D.O., and D.D. Dedhia. 1991. Theoretical and User's Manual for pc-PRAISE, A Probabilistic Fracture Mechanics Computer Code for Piping Reliability Analysis, NUREG/CR-5864, U.S. Nuclear Regulatory Commission, Washington, D.C.

Harris, D.O. 2001. Estimation of the Reliability of Piping at the High Flux Isotope Reactor by Use of the PRAISE Software. Performed by Engineering Mechanics Technology, Inc., San Jose, California to Oak Ridge National Laboratory, Oak Ridge, Tennessee.

Idaho National Engineering and Environmental Laboratory. 1999. Rates of Initiating Events at U.S. Nuclear Power Plant: 1987 - 1997 LOCA Frequency Estimates, NUREG/CR-5750.

Keisler, J., O.K. Chopra, and W.J. Shack. 1994. Statistical Analysis of Fatigue Strain-Life Data for Carbon and Low-Alloy Steels, NUREG/CR-6237.

Keisler, J., O.K. Chopra, and W.J. Shack. 1995. Fatigue Strain-Life Behavior of Carbon and Low-Alloy Steels, Austenitic Stainless Steels, and Alloy 600 in LWR Environments, NUREG/CR-6335. 
Khaleel, M.A., and F.A. Simonen. 1994a. "The Effects of Initial Flaw Sizes and Inservice Inspection on Piping Reliability," Service Experience and Reliability Improvement: Nuclear, Fossil, and Petrochemical Plants, PVP Vol. 288, pp. 95107.

Khaleel, M.A., and F.A. Simonen. 1994b. "A Parametric Approach to Predicting the Effects of Fatigue on Piping Reliability," Service Experience and Reliability Improvement: Nuclear, Fossil, and Petrochemical Plants, PVP Vol. 288, pp. 117125.

Khaleel, M.A., F.A. Simonen, D.O. Harris, and D. Dedhia. 1995a. "The Impact of Inspection on Intergranular Stress Corrosion Cracking for Stainless Steel Piping," Risk and Safety Assessment: Where is the Balance, ASME PVP Vol. 266/SERA-Vol. 3, pp. 411-422.

Khaleel, M.A., and F.A. Simonen. 1995b. “A Model for Predicting Vessel Failure Probabilities Due to Fatigue Crack Growth," Fatigue and Fracture Mechanics in Pressure Vessels and Piping, ASME PVP Vol. 304, pp. 401-416.

Khaleel, M.A., and F.A. Simonen. 1997. "Reliability-Based Inspection Planning for Stainless Steel Piping Under Conditions of Intergranular Stress Corrosion Cracking," Structural Safety and Reliability, Proceedings of ICOSSAR '97 - 7th International Conference on Structural Safety and Reliability, Kyoto, Japan, November 24-28, 1997.

Khaleel, M.A., and F.A. Simonen. 1998. "A Probabilistic Model for Fatigue Crack Initiation and Propagation," Fatigue, Fracture and Residual Stresses, PVP-373, pp. 27-34, American Society of Mechanical Engineers, New York.

Khaleel, M.A., and F.A. Simonen. 1999. "Uncertainty Analyses for Calculated Failure Probabilities of Piping Welds," Pressure Vessel and Piping Codes and Standards - 1999, PVP-Vol. 383, pp. 77-90.

Khaleel, M.A., F.A. Simonen, H.K. Phan, D.O. Harris, and D. Dedhia. 2000. Fatigue Analysis of Components for 60-Year Plant Life, NUREG/CR-6674, prepared by Pacific Northwest National Laboratory for U.S. Nuclear Regulatory Commission.

Lydell, B. 1999. Failure Rates in Barseback-1 Reactor Coolant Pressure Boundary Piping - An Application of a Piping Failure Base, SKI Report 98:30, RSA Technologies, Vista, California.

NASCRAC 90. 1990. NASCRAC ${ }^{T M}$, NASA CRack Analysis Code, Version 2.2, Theory Manual, Failure Analysis Associates, Inc. Menlo Park, California.

Oak Ridge National Laboratory (ORNL). 2001. High Flux Isotope Reactor Updated Safety Analysis Report, ORNL/M-2344/V6, Rev. 3. 
Ramsey, C.T., M.A. Linn, G.F. Flanagan, J.R. Inger, D.H. Cook, and R.B. Rothrock. 2001. Safety Analysis to Resolve the USQ Regarding Discovery of a Cracked Pipe in the HFIR PWD Drain Line, ORNL/RRD/INT-117. Prepared by Research Reactors Division, Oak Ridge National Laboratory, Oak Ridge Tennessee.

Simonen, F.A., and H.H. Woo. 1984. Analyses of the Impact of Inservice Inspection Using a Piping Reliability Model, NUREG/CR-3869, U.S. Nuclear Regulatory Commission, Washington, D.C.

Simonen, F.A., and D.O. Harris. 1998. "Benchmarking of pc-PRAISE and SRRA for Calculations of Low Probabilities of Pipe Breaks," informal report submitted to USNRC by Pacific Northwest National Laboratory, revised September 25, 1998.

Simonen, F.A., and S.R Gosselin. 2000. "Life Prediction and Monitoring of Nuclear Power Plant Components for Service-Related Deregulation," ASME Journal of Pressure Vessel Technology, Vol. 123, pp. 58-64.

U.S. Nuclear Regulatory Commission (NRC). 1999. Technical Elements of Risk-Informed Inspection Programs for Piping - Draft Report, NUREG-1661.

Woo, H.H., and C.K. Chou. 1982a. "Piping Reliability Analysis for Pressurized Water Reactor Feedwater Lines," UCRL-86216, Lawrence Livermore Laboratory, prepared for the ASME Pressure Vessel and Piping Conference, Orlando, Florida, June 27-July 2, 1982.

Woo, H.H., and C.K. Chu. 1982b. Piping Reliability Model Validation and Potential Use for Licensing Regulation Development, NUREG/CR-2801. Prepared for the U.S. Nuclear Regulatory Commission by Lawrence Livermore National Laboratory. 